\title{
Personal Appearance Workers
}

National Cancer Institute

\section{Source}

National Cancer Institute. Personal Appearance Workers. NCI Thesaurus. Code C122496.

Barbers provide services, such as cutting, trimming, shampooing, and styling hair, trimming beards, or giving shaves. Hairdressers, hairstylists, and cosmetologists provide beauty services, such as shampooing, cutting, coloring, and styling hair, and massaging and treating scalp. They may also apply makeup, dress wigs, perform hair removal, and provide nail and skin care services. Makeup artists, theatrical and performance apply makeup to performers to reflect period, setting, and situation of their role. Manicurists and pedicurists clean, shape, and decorate customers' fingernails and toenails. Shampooers clean and rinse customers' hair. Skin care specialists provide skin care treatments to face and body to enhance an individual's appearance. 